\title{
Diversity of root-associated fungi of Rhododendron simsii in subtropical forests: fungal communities with high resistance to anthropogenic disturbances
}

\author{
Yanhua Zhang ${ }^{1} \cdot$ Fangping Tang $^{1} \cdot \operatorname{Jian~} \mathrm{Ni}^{1} \cdot$ \\ Lijia Dong ${ }^{1} \cdot$ Lifu Sun ${ }^{1}$
}

Received: 15 January 2019 / Accepted: 23 April 2019 / Published online: 9 October 2019

(C) The Author(s) 2019

\begin{abstract}
Species of the Ericaceae or heath family are widely distribute in continental ecosystems and their special ericoid mycorrhizas (ERM) are considered beneficial to their survival and persistence in variable habitats. Currently, increasing anthropogenic disturbances and improper forest management are affecting subtropical forests of China where these native species located. These activities not only affect plant communities above-ground, but also impose pressures on microbial communities below- ground. In this study, rootassociated fungal communities of Rhododendron simsii in four forest types under different anthropogenic disturbances were identified using an Illumina Miseq platform, i.e., old growth forests, secondary forests with one cutting (SEC I), secondary forests with two cuttings (SEC II), and Chinesefir plantations (PLF). Intra- and inter-annual variations were analyzed by comparing samples taken in different seasons and years. The results show that: (1) over 1000 OTUs were found in hair roots with most from the division Ascomycota and Basidiomycota belonging to different functional groups;
\end{abstract}

Project funding: This study is supported by the National Natural Science Foundation of China (31170469 and 31700476),

Zhejiang Natural Science Foundation (LY19C030002) and the

Technology Division of Shaoxing (2017B70061).

The online version is available at http://www.springerlink.com.

Corresponding editor: Yu Lei.

Electronic supplementary material The online version of this article (https://doi.org/10.1007/s11676-019-01050-4) contains supplementary material, which is available to authorized users.

Lifu Sun

sunlifu@usx.edu.cn

1 College of Life Sciences, Shaoxing University, Shaoxing 312000, People's Republic of China
(2) while there were a few indicator OTUs specific to different forest types, seasons and years, the proportion of shared taxa was quite large, accounting for $44.9-79.4 \%$ of the total OTUs; (3) significantly positive correlations were found between disturbance sensitivity and temporal variations in common fungal orders, and both in major fungal orders were significantly different among fungal functional groups in which putative and possible ERM fungi were highly resistant to disturbances and low temporal variations. The high disturbance resistance and temporal persistence of putative ERM fungi may be essential for the successful adaptation of $R$. simsii in disturbed subtropical forests of China.

Keywords Rhododendron simsii $\cdot$ Mycorrhiza $\cdot$ Fungal community $\cdot$ Diversity $\cdot$ Subtropical forests $\cdot$ Human disturbance

\section{Introduction}

Rhododendron simsii Planch. is popular as a landscape plant because of its beautiful flowers. It occurs naturally in China, Japan, Laos, Myanmar and Thailand. In most southern provinces of China, $R$. simsii populations occur in subtropical forests, along forest margins and in open upland thickets at 500-2700 m a.s.l. (Editorial Committee of Flora of China, Chinese Academy of Sciences 2006). However, their natural habitats are frequently disturbed by anthropogenic activities. Most Rhododendron species have typical ericoid mycorrhizas (ERM) (Fumiaki et al. 2003; Zhang et al. 2009; Tian et al. 2011), which are considered to be helpful for both the host plant and their fungal partners to be distributed widely in the world (Cázares et al. 2005; Bougoure et al. 2007; Fujimura and Egger 2012; Gorzelak et al. 2012). 
Anthropogenic disturbances and particular types of forest management such as clear-cutting, selective cutting, planting of high-value species, not only influence plant communities above-ground but also underground fungal communities associated with plant roots. For example, ERM fungal communities under different vegetation types such as bogs, rough grazing and forest plantations (Hazard et al. 2014), and arbuscular mycorrhizal fungi (AMF) along an anthropogenic disturbance gradient (Gavito et al. 2008), show significant changes. The results of 378 case studies summarized by Shade et al. (2012) indicated that most soil microbial communities were sensitive to disturbance. In addition, only $23 \%$ of microbial communities recover based on their composition and/or function from 148 cases involved in resilience, (the rate of recovery after disturbance), suggesting that disturbance plays a major role in mycorrhizal fungal and soil microbial communities, but recovery depends on specific conditions.

In this study, intra- and inter-annual variations of fungal communities associated with hair roots of $R$. simsii growing in Chinese subtropical forests were examined across different types of anthropogenic disturbances. Three hypotheses are proposed: (1) fungal communities associated with hair roots of $R$. simsii would be different along the disturbance gradient, across seasons and years; (2) different fungal taxa would show different responses to disturbance and temporal variations; and, (3) disturbance resistance and temporal persistence of fungal functional groups might be correlated, and ERM fungi would be more consistently associated with their $R$. simsii hosts than any other fungal groups.

\section{Materials and methods}

\section{Study site}

Gutianshan National Nature Reserve in Zhejiang Province (GNNR) was selected as the sampling site for this study. Annual average temperatures are above $15{ }^{\circ} \mathrm{C}$ and Annual precipitation are more than $1750 \mathrm{~mm}$. The vegetation of the site is subtropical evergreen broad-leaf forest ( $\mathrm{Yu}$ et al. 2001), and the main soil type is subtropical red soil (Zhang et al. 2011). The dominant species are Castanopsis eyrei (Champ. ex Benth.) Tutcher and Schima superba Gardner \& Champ.

Due to different disturbance histories, there are four distinct types of stands in the GNNR: Chinese- fir (Cunninghamia lanceolata (Lamb.) Hook) plantations (PLF), old growth forests (OGF), secondary forests with one cutting (SEC I), and secondary forests with two cuttings (SEC II). The PLF were planted 20 years ago after clear- cutting of secondary growth forests. The OGF are undisturbed forests located at the heart of the GNNR and have not been harvested or thinned in the past 100 years. Both SEC I and SEC II were clear-cut about 50 years ago, and SEC II was selectively cut 20 years ago. Since the previous disturbances, all stands have naturally regenerated. Twelve 1 -ha $(100 \mathrm{~m} \times 100 \mathrm{~m})$ plots were established with three replicates for each forest type.

\section{Sampling procedure}

Hairy root samples of four $R$. simsii plants were collected from each sample plot over six periods, March, June, September and December of 2012, and March 2013, and March 2014. There were 288 individual samples ( 4 samples $\times 12$ plots $\times 6$ sampling times). The fine roots were collected from soils at four directions around the taproots. After soaking and cleaning in sterile water, 20 (about 1-cm long) hair root segments were randomly selected and put separately into a $1.5 \mathrm{~mL}$ centrifugal tube for DNA extraction. A 200-g soil sample was collected for elemental analyses from the top $10-\mathrm{cm}$ layer of soil around each sample plant.

\section{DNA extraction and Illumina MiSeq sequencing}

DNA was extracted according to Zhang et al. (2016). The ITS1 region special for fungi was selected to be amplified by PCR with 1723 F and 2043R primers; the PCR reaction and amplicons purification procedures are based on Zhang et al. (2017). The Illumina MiSeq sequencing were completed by Shanghai Majorbio Co. Ltd. in China. Raw fastq files were demultiplexed and quality-filtered using QIIME (ver 1.7) following Zhang et al. (2016).

Open reference operational taxonomic unit (OTU) picking was done with pick_open_reference_otus.py using the default uclust method and ITS 12-11 dataset (97\% similarity), and singletons were removed during OTU picking. Single_rarefaction.py in Qiime was used to generate an OTU table with even reads of 10,000 in each root sample. Rare fungal OTUs occurring in only one or two samples out of 72 were not considered in further analyses.

Mean relative abundances $\left(\mathrm{MRA}_{\mathrm{d}}\right)$ of fungal orders under the four forest types were calculated and the disturbance sensitivity of each fungal order defined as the coefficient of variance $\left(\mathrm{CV}_{\mathrm{d}}\right)$ of $\mathrm{MRA}_{\mathrm{d}}$. Mean relative abundances $\left(\mathrm{MRA}_{\mathrm{t}}\right)$ of fungal orders in six sampling times were also calculated and the temporal variation of each fungal order was defined as the coefficient of variance $\left(\mathrm{CV}_{t}\right)$ of $\mathrm{MRA}_{t}$ of sampling times.

\section{Statistical analysis}

The differences population densities and mean $\mathrm{DBH}$ (diameter at breast height) of $R$. simsii between the four forest types was analyzed using one-way ANOVA with SPSS 22.0. The otu_category_significance.py in Qiime 
analyzed and determined the indicator fungal species for the different forest types, seasons, and years. The main influencing factors of root-associated fungal communities were identified with "Envfit" function. The "rda" function in the R package "vegan" performed principal components analysis (PCA), and the first three components (PC1, PC2, and PC3) were used as plant parameters in "envfit". The impacts of forest type, season and year on the community composition of root-associated fungi were evaluated with the "Adonis" function in the R package "vegan".

\section{Results}

\section{Populations of Rhododendron simsii in anthropogenic disturbance sites}

The plant compositions in OGF and two secondary forests (SEC I and SEC II) are similar, but there are more

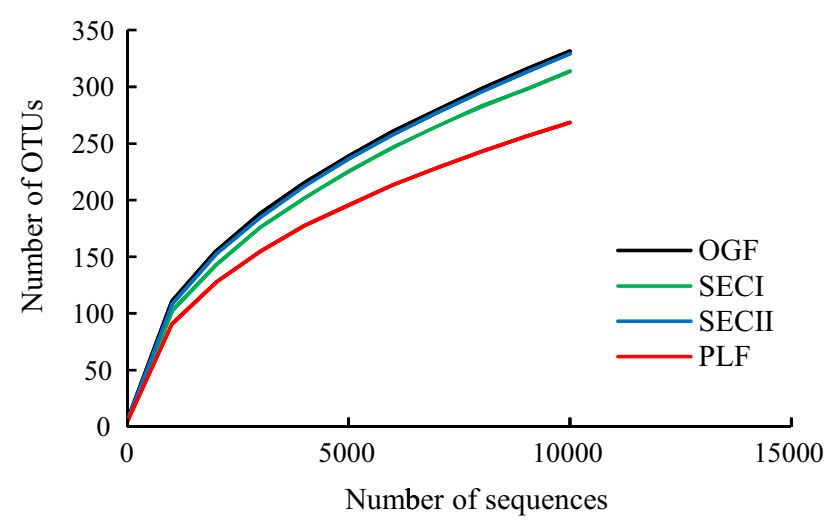

Fig. 1 Rarefaction curves of observed fungal OTUs in hair roots of Rhododendron simsii in forests with different anthropogenic disturbances, i.e., old growth forest (OGF), secondary forest I (SEC I), secondary forest II (SEC II), and plantation (PLF) large-diameter trees in the OGF. The dominant species (Chinese- fir) and plant composition in PLF are obviously different from the secondary and old growth forests. Mean DBH and population density of $R$. simsii in the four forest types are shown in Appendix S1. There were no significant differences in these two parameters among the forest types $(P>0.05)$, although the density was the lowest and mean DBH was the highest in the OGF.

\section{Fungal OTUs in hair roots of Rhododendron simsii}

Rarefaction curves of the observed fungal OTUs in hair roots of $R$. simsii are shown in Fig. 1. Mean observed fungal OTU richness at the sample depth of 10,000 reads were 331,314, 329 and 268 in OGF, SEC I, SEC II and PLF, respectively. There were no significant differences between any two forest types, although the fungal richness in the PLF samples was the lowest.

The number of specific and shared OTUs of the stands under different anthropogenic disturbances, seasons and years is shown in the Venn diagram (Fig. 2). Secondary forests shared more OTUs with OGF compared to the PLF (Fig. 2a). The shared OTUs in all stands were 408, accounting for $36.6 \%$ of the total number in all forest types and $85.2 \%$ of the total reads in each sample. The specific number of fungi were 18, 0, 5 and 24 for the OGF, SEC I, SEC II, and PLF, respectively.

The total number of fungal OTUs were 922, 796, 929 and 883 for the spring, summer, autumn and winter seasons, respectively (Fig. 2b). There were 431 shared OTUs in 2012 over all the seasons, while any two seasons shared over 610 OTUs. More seasonal specific OTUs (35) were found in the spring, compared with the summer, autumn, winter seasons $(8,17$, and 12, respectively). From 2012 to 2014 , the number of OTUs in the spring seasons was 610, 563 and 571, respectively (Fig. 2c), and 447 common OTUs in all 3 years,
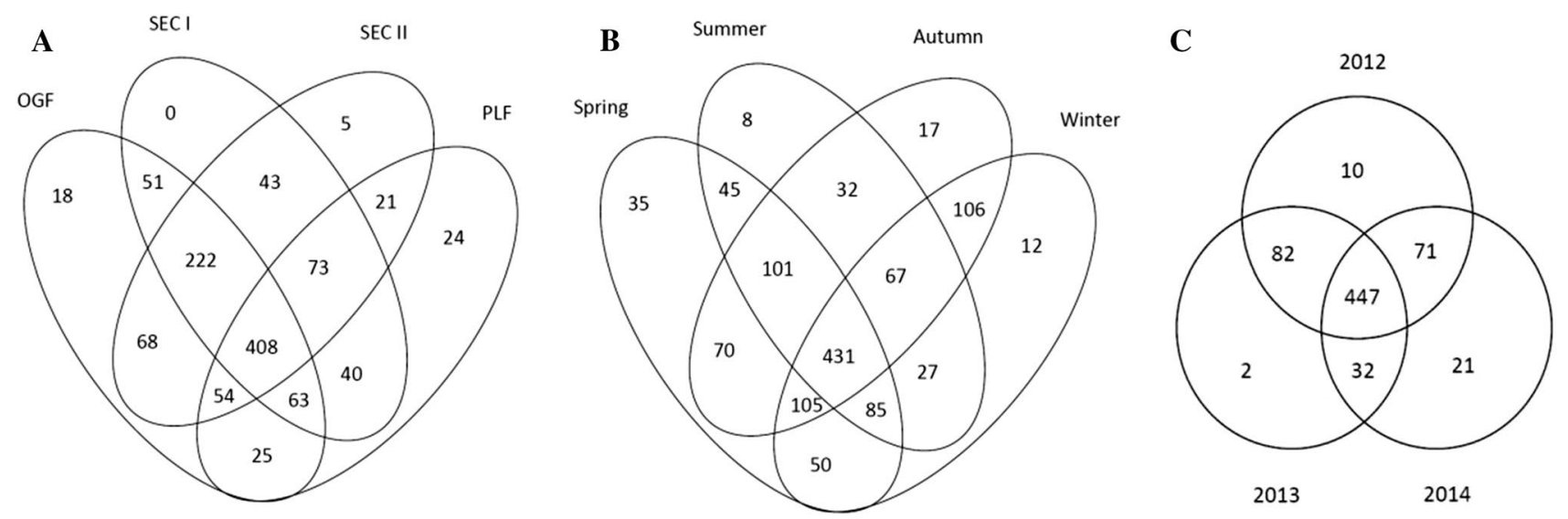

Fig. 2 Venn diagram showing specific and shared OTUs of Rhododendron simsii in forests with different anthropogenic disturbances (a), seasons (b), and years (c). OTUs with frequencies $>5 \%$ in all samples were considered 
accounting for $73.3-79.4 \%$ of the total number. However, there were relatively few specific OTUs for each year.

\section{Fungal community structures}

The phyla and main classes in fungal community compositions under different forest disturbances are shown in Fig. 3. Ascomycota and Basidiomycota were the two dominant phyla in all stand types, accounting for 95.6-98.8\% of the total reads. Other phyla, such as Zygomycota, Glomeromycota and Chytridiomycota were less than $1.2-4.4 \%$ of the total. Common classes of fungi were Leotiomycetes,
Sordariomycetes, Dothideomycetes, Eurotiomycetes, and Pezizomycetes of the Ascomycota, as well as Agaricomycetes and Tremellomycetes of the Basidiomycota.

Principal component analysis (PCA) shows the community structure of root-associated fungi of $R$. simsii at different sampling times with different anthropogenic disturbances (Fig. 4). Community structure in spring and winter were similar in the OGF and SEC I, while they were similar in autumn and winter in SEC II and the PLF. The fungal community structure in the summer was always different than in any other seasons. Over the three sampling years, compositions of root-associated fungal communities were
Fig. 3 Phyla and main classes of root-associated fungi of Rhododendron simsii in forests under different disturbances
Fig. 4 Principal component analysis of root-associated fungi of Rhododendron simsii at different sampling dates in forests with different anthropogenic disturbances
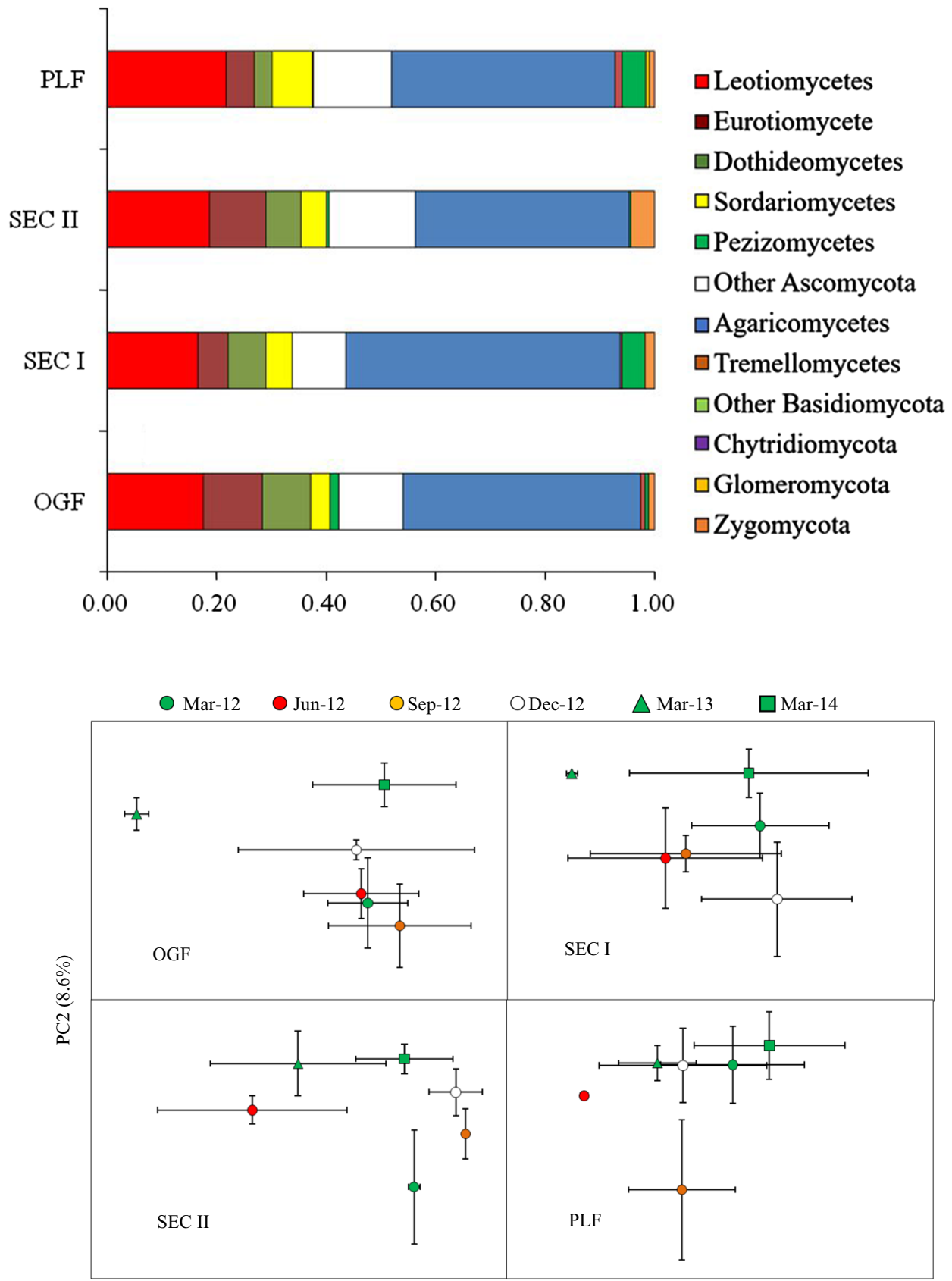

PC1 $(22.3 \%)$ 


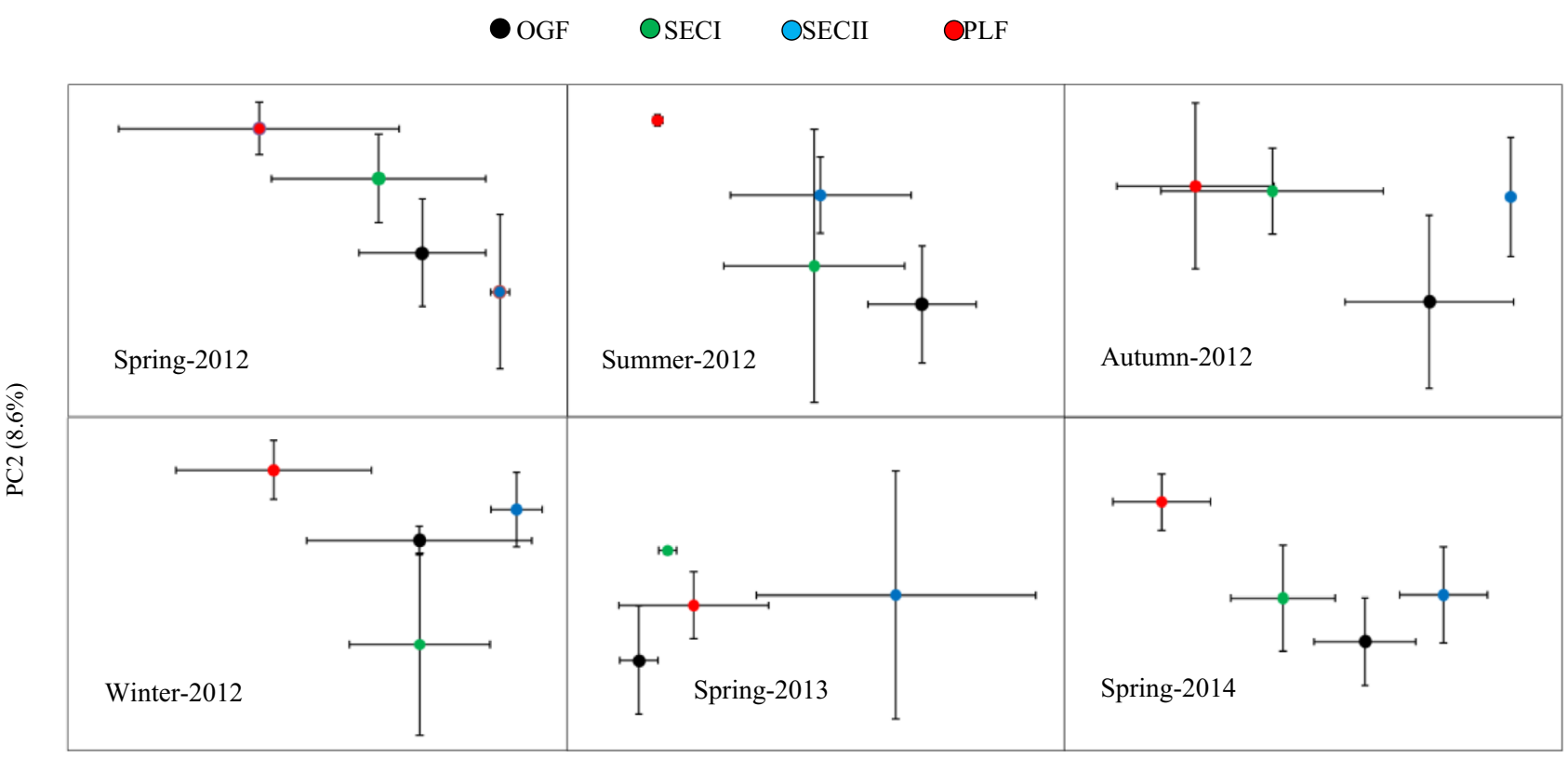

PC1 (22.3\%)

Fig. 5 Principal component analysis of root-associated fungi of Rhododendron simsii in forests with different anthropogenic disturbances at different sampling dates

well separated. PCA results also indicated that the community structure of root-associated fungi was different across seasons and years in each stand, especially based on PC1 (Fig. 5). Community structures in plantations PLF were distinct from others in the spring, summer and winter of 2012, as well as in the spring of 2014. In the springs of the 3 years and the winter of 2012, fungal community structures were similar in the OGF and SEC I, while OGF fungal communities were similar to those under SEC II in in summer and autumn of 2012.

The results of the Adonis analysis shows that the effects of season, year, and forest type on the community composition of root-associated fungi of $R$. simsii were insignificant $(P>0.05)$ for seasons, (although the number of OTUs in summer was less), but significantly different for years and anthropogenic disturbances $(P<0.01)$ (Table 1).

Table 1 Results of Adonis showing the effects of year, season, and forest type on community composition of root-associated fungi of Rhododendron simsii

\begin{tabular}{lrllr}
\hline Items & $\mathrm{d} f$ & MS & $F$ & \multicolumn{1}{l}{$P$} \\
\hline Year & 2 & 1.919 & 3.4751 & $<0.001$ \\
Season & 3 & 1.187 & 1.4332 & 0.058 \\
Forest type & 3 & 2.668 & 3.2201 & $<0.001$ \\
Residuals & 63 & 0.276 & & \\
\hline
\end{tabular}

$\mathrm{d} f$ degree of freedom; $M S$ mean square

\section{Factors affecting fungal community associated with Rhododendron simsii hair roots}

Our results show that plant community, rather than soil parameters and climatic factors, had significant effects on root-associated fungal communities (Table 2). For plant communities, based on principal component 2(PC2), the proportions of AM (arbuscular mycorrhiza), ECM (ectomycorrhizal) and ERM plants were significant different. The plant species contributing significantly to PC2 included two species associated with arbuscular mycorrhizas, Cunninghamia lanceolata and Syzygium buxifolium Hook. et Arn, two dominant species in subtropical forests associated with ectomycorrhizal fungi, Castanopsis eyrei and Lithocarpus glaber (Thunb.) Nakai, as well as a common species associated with ericoid mycorrhizas, Vaccinium carlesii Dunn. These results indicate that both dominant trees and common neighbors associated with ERM may affect the fungal communities of $R$. simsii hosts. The AM: ECM: ERM ratios also show significant effects on the root-associated fungal communities. Soils or climatic parameters were insignificant on root-associated fungal communities of $R$. simsii.

\section{Indicator fungal species of stands with different anthropogenic disturbances}

There were five fungal OTUs showing significant preference to a specific forest type (Table 3 ). The number of 
Table 2 Correlations of microbial community composition with plant community, and edaphic and climatic factors

\begin{tabular}{|c|c|c|c|c|}
\hline & RDA1 & RDA2 & $r^{2}$ & $P$ \\
\hline \multicolumn{5}{|c|}{ Plant community } \\
\hline Richness & 0.983 & -0.184 & 0.004 & 0.866 \\
\hline TABH & -0.959 & -0.283 & 0.047 & 0.184 \\
\hline $\mathrm{PC} 1$ & 0.610 & 0.792 & 0.019 & 0.515 \\
\hline $\mathrm{PC} 2$ & 0.998 & 0.069 & 0.179 & $<0.001$ \\
\hline PC3 & -0.028 & 1.000 & 0.011 & 0.682 \\
\hline P.AM & -0.963 & -0.268 & 0.157 & 0.003 \\
\hline P.ECM & 0.982 & 0.187 & 0.125 & 0.009 \\
\hline P.ERM & 0.930 & 0.366 & 0.140 & 0.005 \\
\hline \multicolumn{5}{|c|}{ Edaphic parameters } \\
\hline SOC & 0.612 & -0.791 & 0.035 & 0.290 \\
\hline TN & 0.508 & -0.862 & 0.024 & 0.428 \\
\hline $\mathrm{TP}$ & -0.741 & -0.672 & 0.057 & 0.129 \\
\hline $\mathrm{NH}_{4}^{+}-\mathrm{N}$ & -0.097 & -0.995 & 0.023 & 0.463 \\
\hline $\mathrm{NO}_{3}{ }^{-}-\mathrm{N}$ & 0.936 & 0.353 & 0.019 & 0.525 \\
\hline AP & -0.170 & -0.985 & 0.031 & 0.342 \\
\hline $\mathrm{pH}$ & -0.033 & -1.000 & 0.001 & 0.954 \\
\hline \multicolumn{5}{|c|}{ Climatic factors } \\
\hline MMT & -0.993 & 0.116 & 0.037 & 0.282 \\
\hline MMP & 0.841 & 0.542 & 0.044 & 0.222 \\
\hline
\end{tabular}

TABH is total area at breast height; PC1, PC2 and PC3: the first three principal components of plant community; SOC is soil organic carbon; STN is soil total nitrogen content; STP is soil total phosphorus content; $\mathrm{NH}_{4}{ }^{+}-\mathrm{N}$ is ammonium nitrogen; $\mathrm{NO}_{3}{ }^{-}-\mathrm{N}$ is nitrate nitrogen; AP is Available phosphorus; MMT is monthly mean temperature; MMP is monthly mean precipitation

Table 3 Indicator fungal species for forests with different anthropogenic disturbances and over three sampling years

\begin{tabular}{llllc}
\hline Index & Identified name & Group & $P$ & Post-hoc test \\
\hline Disturbance & Herpotrichiellaceae 1 & PLF & $<0.001$ & 0.029 \\
& Unidentified Ascomy- & PLF & $<0.001$ & 0.006 \\
$\quad$ cota 1 & & & \\
& Unidentified fungus 1 & OGF & $<0.001$ & 0.020 \\
& Lecanicillium sp. & OGF & $<0.001$ & $<0.001$ \\
& Unidentified fungus 2 & OGF & $<0.001$ & 0.030 \\
Myxotrichaceae 1 & 2013 & $<0.001$ & 0.027 \\
Year & Phialocephala fortinii & 2013 & $<0.001$ & 0.037 \\
& Clavulina sp. & 2014 & $<0.001$ & 0.000 \\
& Helotiales 1 & 2014 & $<0.001$ & 0.000 \\
& Penicillium sp. 2 & 2014 & $<0.001$ & 0.000 \\
& Sebacinaceae 1 & 2014 & $<0.001$ & 0.025 \\
& Sebacinales 1 & 2014 & $<0.001$ & 0.000 \\
& Sebacinales 2 & 2014 & $<0.001$ & 0.014 \\
& Tomentella sp. & 2014 & $<0.001$ & 0.043 \\
& Unidentified Ascomy- & 2014 & $<0.001$ & 0.050 \\
cota 2 & & & \\
& Unidentified fungus 3 & 2014 & $<0.001$ & 0.031 \\
\hline
\end{tabular}

indicator species to OGF, SECI, SECII, and PLF were 3, 0,0 , and 2 , respectively. There was no significant indicator for seasons. Eleven indicator species emerged in 2013 and 2014. Fungal species in families such as Herpotrichiellaceae 1, Myxotrichaceae 1, and Sebacinaceae 1 and orders such as Helotiales 1, Sebacinales 1 and Sebacinales 2 might be potential ericoid mycorrhizal fungi. Phialocephala fortinii was a putative DSE (dark septate endophyte), Tomentella sp. was a kind of ECMF, Penicillium sp. was a saprophytic species or pathogen, and Lecanicillium sp. was identified as a plant pathogen according to Tedersoo et al. (2014).

\section{Disturbance sensitivity and temporal variations of functional fungal groups associated with hair roots of Rhododendron simsii}

Fungal orders associated with hair roots of $R$. simsii were divided into five groups, e.g., putative ERMF, possible ERMF, putative ECMF, AMF, and fungal orders without identified functions (Table 4). These orders ranged from very sensitive to relatively tolerant of anthropogenic

Table 4 The disturbance sensitivity and temporal variations of major fungal orders with functional groups associated with hair roots of $R$. simsii

\begin{tabular}{llcc}
\hline Fungal order & Functional group & $\begin{array}{l}\text { Disturbance } \\
\text { sensitivity }\end{array}$ & $\begin{array}{c}\text { Temporal } \\
\text { variations }\end{array}$ \\
\hline Helotiales & Putative ERM fungi & 8.4 & 45.7 \\
Sebacinales & Putative ERM fungi & 67.9 & 50.0 \\
Hypocreales & Putative ERM fungi & 37.2 & 43.0 \\
Chaetothyriales & Putative ERM fungi & 41.8 & 52.9 \\
Xylariales & Putative ERM fungi & 32.4 & 23.3 \\
Sordariales & Putative ERM fungi & 99.1 & 109.1 \\
Tremellales & Possible ERM fungi & 95.9 & 125.7 \\
Capnodiales & Possible ERM fungi & 30.1 & 81.1 \\
Mortierellales & Possible ERM fungi & 43.4 & 58.9 \\
Chaetosphaeriales & Possible ERM fungi & 59.2 & 33.8 \\
Pleosporales & Possible ERM fungi & 77.7 & 61.5 \\
Saccharomycetales & Possible ERM fungi & 54.4 & 106.1 \\
Lecanorales & Possible ERM fungi & 75.8 & 68.7 \\
Thelephorales & Putative ECM fungi & 35.6 & 10.9 \\
Russulales & Putative ECM fungi & 69.9 & 62.2 \\
Agaricales* & Putative ECM fungi & 43.4 & 49.9 \\
Boletales & Putative ECM fungi & 116.4 & 131.1 \\
Archaeosporales & AM fungi & 200.0 & 244.9 \\
Glomerales & AM fungi & 163.6 & 201.1 \\
Diversisporales & AM fungi & 180.9 & 131.3 \\
\hline
\end{tabular}

*Over 50\% reads of identified OTUs in Agaricales were ECM fungal taxa (e.g. Cortinarius, Piloderma, Tylospora, and Amanita), and Agaricales were grouped into putative ECM fungi 


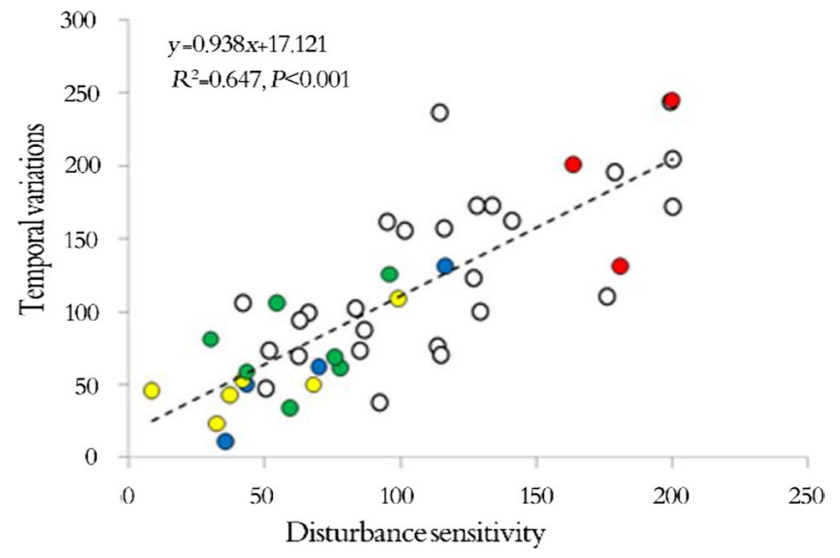

Fig. 6 Relationship between disturbance sensitivity and temporal variations of major functional fungal orders associated with hair roots of Rhododendron simsii (Yellow is putative ERM order, Green is possible ERM order, Blue is putative ECM order, Red is AM order, White is nonfunctional fungal order)

disturbances and temporal variations. The order Helotiales had the lowest $\mathrm{CV}_{\mathrm{d}}$ (coefficient of variation to disturbance), indicating that it had the highest tolerance to logging and commercial planting. It also showed that AM fungi were more sensitive to anthropogenic disturbances, which may be due to the appearance of a large number of AMF's hosts introduced by tree planting in PLF.

For temporal variations of fungal orders, $\mathrm{CV}_{\mathrm{t}}$ (coefficient of variation to time) values were (mean $\pm \mathrm{SE}$ ) $54.0 \pm 11.8,76.5 \pm 11.7,63.5 \pm 25.0$, and $192.4 \pm 33.1$ for putative ERM fungi, possible ERM fungi, putative ECM fungi and AM fungi, respectively (Table 4). Significantly positive correlations were found between disturbance sensitivity and temporal variations $\left(R^{2}=0.647, P<0.001\right.$; Fig. 6).

\section{Discussion}

\section{Diversity of fungi associated with hair roots of Rhododendron simsii}

Based on high through-put sequencing, Ascomycota and Basidiomycota were the dominant phyla in root-associated fungal communities of $R$. simsii, while Zygomycota, Glomeromycota and Chytridiomycota were present in relative lower abundance, similar to those observed in Vaccinium spp.; however, the 1115 OTUs in the roots of $R$. simsii were much less than those on roots of Vaccinium carlesii (over 5000 OTUs) in the same forests (Zhang et al. 2016). Some putative ERMF orders such as Helotiales and Sebacinales were also found on roots of other ericaceous plants (Xiao 1994; Read 1996; Piercey et al. 2002; Midgley et al. 2004;
Mark 2006; Selosse et al. 2007; Walker et al. 2011; Weiß et al. 2011), and were also observed in this study. Besides putative ERM fungal taxa, other fungi, for example, DSE (Phialocephala fortinii), ECM fungi (species of Tomentella and Russula), AM fungi (species of Glomeromycota), saprophytic or pathogenic fungi (e.g. species of Penicillium and Lecanicillium), were found in these fungal communities and they were considered to play either positive or negative roles for their hosts in different environments. These fungal taxa were also observed in other research on ericaceous plants (Phuwiwat and Soytong 2001; Zare and Gams 2001; Allen et al. 2003; Walker et al. 2011; Wurzburger et al. 2011; Sun et al. 2012), and their functions on roots of ericaceous plants should be evaluated in further studies.

\section{Determinants of root-associated fungal communities of Rhododendron simsii}

PC2 and the AM: ECM: ERM proportions in the forest types, in which the mycorrhizal hosts belonged to different families, showed significant effects on root-associated fungal communities of $R$. simsii (Table 3). The most significant impact on the proportional changes of plants was the introduction of Cunninghamia lanceolata, the single dominant tree species that could stimulate the plant community to host more AM fungi (Bruelheide et al. 2011). Another impact was from clear-cutting and select-cutting (focused on local dominant tree species), and both would alter the fungal proportions maintained by native dominant tree species together with ECM fungi (i.e., Pinus massoniana Lamb. of the Pinaceae and Castanopsis eyrei and Castanopsis carlesii (Hemsl.) Hay. of the Fagaceae) and AM fungi (i.e., Schima superba of the Theaceae, Daphniphyllum oldhami (Hemsl.) Rosenth. of the Daphniphyllaceae), as well as ERM fungi (i.e., Vaccinium carlesii).

Compared with PC2, more ericaceous species such as Rhododendron ovatum and $R$. latoucheae, and other species such as Corylopsis glandulifera Hemsl. and Loropetalum chinense ( $\mathrm{R}$. Br.) Oliv.of the Hamamelidaceae family significantly contributed to PC3, however, the fungal communities on $R$. simsii roots have not shown obvious effects. Therefore, root-associated fungi of $R$. simsii were influenced by the combination of AM, ECM and ERM fungi on plant roots instead of more ERM hosts. It has also been welldocumented that fungal diversity and fungal community composition in soil and on plant roots are driven by plant community composition (Wu et al. 2012), and that high plant diversity and productivity support high fungal diversity (Schadt et al. 2003; Carney and Matson 2006; Dumbrell et al. 2011). From this point of view, it is easy to understand that the total number of OTUs in PLF was less due to its simple plant community composition and its low productivity compared with OGF and the two secondary forests. 
Typical ECM fungi found on the roots of $R$. simsii and the AM: ECM: ERM proportions of plant community had significant effects on root-associated fungal communities of $R$. simsii (Tables 2, 3 and 4). Mycorrhizal connections formed by ERM fungi have been found between ECM and ERM plant species such as Quercus ilex L. (Fagaceae, with ECM) and Erica arborea L.(Ericaceae, with ERM) (Bergero et al. 2000), and Pinus sylvestris L. (Pinaceae, with ECM) and Vaccinium vitis-idaea L. (Ericaceae, with ERM) (Grelet et al. 2009, 2010). The same fungal association such as on Rhizoscyphus ericae (putative ERM) and ECM have also been observed on roots of ericaceous plants (Wurzburger et al. 2011; Wu et al. 2012; Zhang et al. 2016). This suggests that in a natural ecosystem, mycorrhizal fungi could form common mycelia networks that connect plants (Johnson and Gilbert 2015). Mycorrhizal networks formed between ECM and ERM hosts may be essential for species coexistence and ecosystem functioning in subtropical forests in China, and perhaps for forests in general. However, other tree species, such as exotics, introduced into local forests, would carry their own specific fungi and other microbes with them, resulting in fungal communities becoming even more complex.

From this investigation, soil parameters and climatic factors did not have significant effects on fungal community composition on roots of $R$. simsii (Table 2). In some studies, on fungal communities along nitrogen or $\mathrm{pH}$ gradients, nitrogen levels and $\mathrm{pH}$ had significant effects (Zijlstra 2006; Hofland-Zijlstra and Berendse 2010; Fujimura and Egger 2012). In our study of root-associated fungi of V. carlesii, soil organic carbon, total nitrogen content, total phosphorus content and ammonium nitrogen content significantly affected fungal community composition (Zhang et al. 2016). However, in this study, fungal communities on roots of $R$. simsii were insensitive to edaphic or climatic factors and more responsive to plant community compositions, indicating that different ericaceous species depend on different determinants for their root-associated fungi. This is further evidence for the popularity of $R$. simsii compared to other ericaceous plants.

\section{Disturbance resistance and temporal variations of root-associated fungi}

A large number of OTUs was shared by all stand types (Fig. 2), and the number of their specific OTUs was limited (Fig. 2 and Table 3), indicating that root-associated fungal community composition and structure on $R$. simsii hair roots was adaptive and relatively stable under anthropogenic disturbances. According to all organisms that directly contribute to a particular functional process in an ecosystem (Allison and Martiny 2008), these shared OTUs were divided into different functional groups. High disturbance tolerance (or low disturbance sensitivity) and community resilience may result from taxa either surviving the disturbance or being able to rapidly re-colonize the disturbed area (Lekberg et al. 2012). The high density of $R$. simsii plants in secondary forests and in plantations after at least 20 years (Appendix S1), and putative ERM fungal taxa showed relatively high disturbance resistance, also explains why both host populations and fungal communities were strongly competitive in secondary succession. The proportion of functional fungus groups changed along the restoration period as SEC II, SEC I and OGF. Hutton et al. (1997) also observed that ericoid mycorrhizal colonization on disturbed sites returned to levels comparable to undisturbed sites after 12 years regeneration from disturbance, and the recovery was much faster than soil microbial communities in oak forests 100 years after anthropogenic disturbances (Fichtner et al. 2014). The gap between microbial taxa to resistance (insensitivity to disturbance), and resilience (the rate of recovery after disturbance), was larger (Lekberg et al. 2012). Furthermore, compared with resistance, resilience investigation was less. Shade et al. (2012) noted that only $23 \%$ of 148 resilient- examined cases on composition and/or function of soil microbes could return to a pre-disturbance state. Under a greater disturbance, soil microbes could never fully recover even if the recovery time was longer. ERM fungi and the recovery of the hosts was short. It is not clear whether functional mycorrhizal fungi of R. simsii in disturbed forests (PLF, SEC I and SEC II) would be recruited continuously into fungi communities as in OGF. But the relative stability and resilience of root-associated fungal communities, especially these functional fungi, must be essential for survival and growth of ericaceous plants in disturbed forests.

Significant temporal variations of root-associated fungal communities of $R$. simsii were observed and inter-annual (between 2 years) variations were higher than intra-annual (within a year) variations (Table 1). Significant correlations were found between disturbance sensitivity and temporal variation of fungal taxa (Fig. 6), and functional fungal groups showed different responses to $\mathrm{CV}_{\mathrm{d}}$ and $\mathrm{CV}_{\mathrm{t}}$, implying that fungal taxa with greater resistance to disturbance would be observed more constantly in different seasons and years. Putative and possible ERM fungal orders were relatively higher resistant to disturbances and had lower temporal variations; however, non-essential taxa were occasionally observed with lower disturbance resistance and higher temporal variations. The study site experienced an extreme drought and high temperatures during the summer of 2013, and the fungal communities of the spring of 2014 were similar to those of the 2012 spring (Fig. 4). The distinction of fungal communities in spring of the 3 years and the flourish of indicator species for the year 2014 could be partially due to the inter-annual shifts of climatic factors and partially to the succession of fungi. Cázares et al. (2005) proposed that 
non-mycorrhizae prevailed in the earliest stages with some DSE, ECM and ERM plants, but the three would become equally dominant plants over time. Comparing early and mature successional stages with different vegetation in subtropical forests of Australia and the United States, Dickie et al. (2013) found that even though both stages had similar mycorrhizal and non-mycorrhizal hosts, in the mature stages only orchid mycorrhiza emerged. In OGF, populations of $R$. simsii tended to decline even though their mycorrhizal composition and structure were the best. In order to accompany dominant trees in subtropical forests with succession, $R$. simsii has significant support from their mycorrhizal associations, and sustainable and stable ERM fungi is necessary.

\section{Conclusions}

This study on root-associated fungal communities of $R$. simsii investigated over 1000 operational taxonomic units and determined that were mainly in the Ascomycota and Basidiomycota phyla. The results show the effects of time and different forest types under anthropogenic disturbances on fungal communities, although the proportion of shared operational taxonomic units remained large, accounting for $44.9-79.4 \%$ of the total number. The changes in plant communities with different mycorrhizal associations significantly affected root-associated fungal communities of $R$. simsii, while soil and climatic factors had negligible effects.

The disturbance sensitivity and temporal variations of major fungal orders were significantly different among fungal functional groups, and putative and possible ericoid mycorrhizal fungi were highly resistant to disturbances and low temporal variations. There were significantly positive correlations between disturbance sensitivity and temporal variations of common fungal orders. The high disturbance resistance and temporal persistence of putative ericoid mycorrhizal fungal taxa may be essential for successful adaptation of $R$. simsii in disturbed subtropical forests of China.

Acknowledgements We thank Dr. Xiaojuan Liu for providing climatic information of the sampling sites, and Yefei Jin and Li Han for preparing the material and experiments.

Open Access This article is distributed under the terms of the Creative Commons Attribution 4.0 International License (http://creativeco mmons.org/licenses/by/4.0/), which permits unrestricted use, distribution, and reproduction in any medium, provided you give appropriate credit to the original author(s) and the source, provide a link to the Creative Commons license, and indicate if changes were made.

\section{References}

Allen TR, Millar T, Berch SM, Berbee ML (2003) Culturing and direct DNA extraction find different fungi from the same ericoid mycorrhizal roots. New Phytol 160:255-272

Allison SD, Martiny JBH (2008) Resistance, resilience, and redundancy in microbial communities. PNAS 105(suppl. 1):11512-11519

Bergero R, Perotto S, Girlanda M, Vidano G, Luppi AM (2000) Ericoid mycorrhizal fungi are common root associates of a Mediterranean ectomycorrhizal plant (Quercus ilex). Mol Ecol 9(10):1639-1649

Bougoure DS, Parkin PI, Cairney JWG (2007) Diversity of fungi in hair roots of Ericaceae varies along a vegetation gradient. Mol Ecol 16:4624-4636

Bruelheide H, Böhnke M, Both S, Fang T, Thorsten A, Martin B, Jürgen B, Francois B, Xy Chen, By Ding, Walter D, Alexandra E, Markus F, Geißler C, Guo DL, Werner H, He JS, Andy H, Wenzel K, Bernhard S (2011) Community assembly during secondary forest succession in a Chinese subtropical forest. Ecol Monogr $81: 25-41$

Carney KM, Matson PA (2006) The influence of tropical plant diversity and composition on soil microbial communities. Microbial Ecol $52: 226-238$

Cázares E, Trappe JM, Jumpponen A (2005) Mycorrhiza-plant colonization patterns on a subalpine glacier forefront as a model system of primary succession. Mycorrhiza 15:405-416

Dickie IA, Martínez-García LB, Koele N, Grelet GA, Tylianakis JM, Peltzer DA, Richardson SJ (2013) Mycorrhizas and mycorrhizal fungal communities throughout ecosystem development. Plant Soil 367(1-2):11-39

Dumbrell AJ, Ashton PD, Aziz N, Feng G, Nelson M (2011) Distinct seasonal assemblages of arbuscular mycorrhizal fungi revealed by massively parallel pyrosequencing. New Phytol 190:794-804

Editorial Committee of Flora of China, Chinese Academy of Sciences (2006) Flora of China, vol 57(2). Science Press, Beijing, pp 386-388

Fichtner A, von Oheimb G, Härdtle W, Wilken C, Gutknecht JLM (2014) Effects of anthropogenic disturbances on soil microbial communities in oak forests persist for more than 100 years. Soil Biol Biochem 70:79-87

Fujimura KE, Egger KN (2012) Host plant and environment influence community assembly of High Arctic root-associated fungal communities. Fungal Ecol 5:409-418

Fumiaki U, Junichi PA, Makoto K (2003) Diversity of ericoid mycorrhizal fungi isolated from hair roots of Rhododendron obtusum var. kaempferi in a Japanese red pine forest. Mycoscience 44:97-102

Gavito ME, Pérez-Castillo D, González-Monterrubio CF, VieyraHernández T, Martínez-Trujillo M (2008) High compatibility between arbuscular mycorrhizal fungal communities and seedlings of different land use types in a tropical dry ecosystem. Mycorrhiza 19:47-60

Gorzelak MA, Hambleton S, Massicotte HB (2012) Community structure of ericoid mycorrhizas and root-associated fungi of Vaccinium membranaceum across an elevation gradient in the Canadian Rocky Mountains. Fungal Ecol 5:36-45

Grelet GA, Johnson D, Paterson E, Anderson IC, Alexander IJ (2009) Reciprocal carbon and nitrogen transfer between an ericaceous dwarf shrub and fungi isolated from Piceirhiza bicolorata ectomycorrhizas. New Phytol 182:359-366

Grelet GA, Johnson D, Vrålstad T, Alexander IJ, Anderson IC (2010) New insights into the mycorrhizal Rhizoscyphus ericae aggregate: spatial structure and co-colonization of ectomycorrhizal and ericoid roots. New Phytol 188:210-222 
Hazard C, Gosling P, Mitchell DT, Doohan FM, Bending GD (2014) Diversity of fungi associated with hair roots of ericaceous plants is affected by land use. FEMS Microbiol Ecol 87:586-600

Hofland-Zijlstra JD, Berendse F (2010) Effects of litters with different concentrations of phenolics on the competition between Calluna vulgaris and Deschampsia flexuosa. Plant Soil 327(1):131-141

Hutton BJ, Dixon KW, Sivasithamparam K, Pate JS (1997) Effect of habitat disturbance on inoculum potential of ericoid endophytes of Western Australian heaths (Epacridaceae). New Phytol 135:739-744

Johnson D, Gilbert L (2015) Interplant signaling through hyphal networks. New Phytol 205:1448-1453

Lekberg Y, Schnoor T, KjØler R, Gibbons SM, Hansen LH, Al-Soud WA, SØrensen SJ, Rosendah S (2012) 454-sequencing reveals stochastic local reassembly and high disturbance tolerance within arbuscular mycorrhizal fungal communities. J Ecol 100:151-160

Mark CB (2006) Understanding the roles of multifunctional mycorrhizal and endophytic fungi. In: Schulz B (ed) Microbial root endophytes. Springer, Berlin, pp 281-298

Midgley DJ, Chambers SM, Cairney JWG (2004) Distribution of ericoid mycorrhizal endophytes and root-associated fungi in neighbouring Ericaceae plants in the field. Plant Soil 259:137-151

Phuwiwat W, Soytong K (2001) The effect of Penicillium notatum on plant growth. Fungal Divers 8:143-148

Piercey MM, Thormann MN, Currah RS (2002) Saprobic characteristics of three fungal taxa from Ericaceae roots and their association with the roots of Rhododendron groenlandicum and Picea mariana in culture. Mycorrhiza 12:175-180

Read DJ (1996) The structure and function of Ericoid Mycorrhizal. Ann Bot 77:365-374

Schadt CW, Martin AP, Lipson DA, Schmidt SK (2003) Seasonal dynamics of previously unknown fungal lineages in tundra soils. Science 301:1359-1361

Selosse MA, Setaro S, Glatard F, Richard F, Urcelay C, Weiß M (2007) Sebacinales are common mycorrhizal associates of Ericaceae. New Phytol 174:864-878

Shade A, Peter H, Allison SD, Baho D, Berga M, Bürgmann H, Matulich KL, Huber DH, Langenheder S, Lennon JT, Martiny JBH, Matulich KL, Schmidt TM, Handelsman J (2012) Fundamentals of microbial community resistance and resilience. Front Microbiol 3:1-19

Sun LF, Pei KQ, Wang F, Ding Q, Bing YH, Gao B, Zheng Y, Liang Y, Ma KP (2012) Different distribution patterns between putative ericoid mycorrhizal and other fungal assemblages in roots of Rhododendron decorum in the southwest of China. PLoS ONE 7:e49867

Tedersoo L, Bahram M, Põlme S, Kõljalg U, Yorou NS, Wijesundera R, Ruiz LV, Vasco-Palacios AM, Thu PQ, Suija A, Smith ME, Sharp C, Saluveer E, Saitta A, Rosas M, Riit T, Ratkowsky D, Pritsch K, Põldmaa K, Piepenbring M, Phosri C, Peterson M, Parts K, Pärtel K, Otsing E, Nouhra E, Njouonkou AL, Nilsson RH, Morgado LN, Mayor J, May TW, Majukim L, Lodge DJ, Lee SS, Larsson KH, Kohout P, Hosaka K, Hiiesalu I, Henkel TW, Harend H, Guo LD, Greslebin A, Gretlet G, Geml J, Gates G,
Dunstan W, Dunk C, Drenkhan R, Dearnaley J, Kesel AD, Dang T, Chen X, Buegger F, Brearley FQ, Bonito G, Anslan S, Abell S, Abarenkov K (2014) Global diversity and geography of soil fungi. Science 346:1256688

Tian W, Zhang C, Qiao P, Milne R (2011) Diversity of culturable ericoid mycorrhizal fungi of Rhododendron decorum in Yunnan, China. Mycologia 103:703-709

Walker JF, Aldrich WL, Riffel A, Barbare H, Simpson NB, Trowbridge J, Jumpponen A (2011) Diverse Helotiales associated with the roots of three species of Arctic Ericaceae provide no evidence for host specificity. New Phytol 191:515-527

Weiß M, Sýkorová Z, Garnica S, Riess K, Martos F, Krause C, Oberwinkler F, Bauer R, Redecker D (2011) Sebacinales everywhere: previously overlooked ubiquitous fungal endophytes. PLoS ONE 6:e16793

Wu YT, Gutknecht J, Nadrowski K, Geißler C, Kühn P, Scholten T, Both S, Erfmeier A, Böhnke M, Bruelheide H, Wubet T, Buscot F (2012) Relationships between soil microorganisms, plant communities, and soil characteristics in Chinese subtropical forests. Ecosystems 15:624-636

Wurzburger N, Higgins BP, Hendrick RL (2011) Ericoid mycorrhizal root fungi and their multicopper oxidases from a temperate forest shrub. Ecol Evol 2:65-79

Xiao GP (1994) The role of root-associated fungi in the dominance of Gaultheria shallon. The University of British Columbia, Columbia, pp 1-148

Yu MJ, Hu ZH, Yu JP, Ding BY, Fang T (2001) Forest vegetation types in Gutianshan Natural Reserve in Zhejiang. J Zhejiang Univ Sci 27:375-380

Zare R, Gams W (2001) A revision of Verticillium section Prostrata. IV. The genera Lecanicillium and Simplicillium gen. nov.). Nova Hedwigia 73(1-2):1-50. https://doi.org/10.1127/nova.hedwi gia/73/2001/1

Zhang CY, Yin LJ, Dai SL (2009) Diversity of root-associated fungal endophytes in Rhododendron fortunei in subtropical forests of China. Mycorrhiza 19:417-423

Zhang LW, Mi XC, Shao HB, Ma KP (2011) Strong plant-soil associations in a heterogeneous subtropical broad-leaved forest. Plant Soil 347:211-220

Zhang YH, Ni J, Tang FP, Pei KQ, Luo YQ, Jiang LF, Sun LF, Liang Y (2016) Root associated fungi of Vaccinium carlesii in subtropical forests of China: intra- and inter-annual variability and impacts of human disturbances. Sci Rep 6:22399

Zhang YH, Ni J, Tang FP, Pei KQ, Jiang LF, Pei KQ, Guo TR, Sun LF, Liang Y (2017) The effects of different human disturbance regimes on root fungal diversity of Rhododendron ovatum in subtropical forests of China. Can J For Res 47:659-666

Zijlstra J (2006) Organic nitrogen uptake and endophytic, mutualistic fungi in Dutch heathland ecosystems. PhD thesis, Wageningen University, Wageningen, The Netherlands, pp 1-191

Publisher's Note Springer Nature remains neutral with regard to jurisdictional claims in published maps and institutional affiliations. 